\title{
EXPERIMENTANDO AS JUVENTUDES NUM BAIRRO SEGREGADO
}

Recebido em: 22/07/2009

Aceito em: 27/01/2010

Edmilson Santos dos Santos

Universidade Federal do Rio Grande do Sul (UFRGS)

Porto Alegre - RS - Brasil

RESUMO: Produzir políticas públicas que possibilitem que as comunidades conquistem patamares cada vez mais superiores de qualidade de vida passa por compreender o papel desempenhado pelo Estado na formação das identidades juvenis. Compreender essa dinâmica no bairro Mário Quintana, em Porto Alegre, foi oobjetivo principal deste trabalho. Para tanto, utilizou-se duas estratégias para análise deste contexto: o Mapa do Lazer Juvenil e o Mapa dos Espaços Esportivos. O primeiro buscando compreender o comportamento de lazer dos jovens e o segundo, de que forma os espaços se articulam com esta realidade. Como pudemos perceber, a degradação das condições de existência possui uma relação direta com a diminuição dos projetos de identidades a serem experimentados pela juventude. A falta de acesso aos serviços de lazer oferecidos por parte do Estado acaba aprofundando a vulnerabilidade vivida por jovens moradores da periferia da cidade.

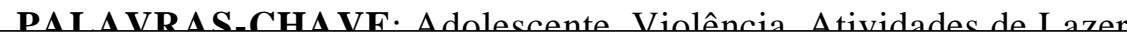

\section{EXPERIENCING DIFFERENT KINDS OF YOUTH IN A SEGREGATED AREA}

ABSTRACT: Producing public policies that enable communities to achieve higher levels of life quality involves understanding the role played by the State in the formation of juvenile identities. Understanding this dynamics in Mario Quintana area, in Porto Alegre, has been the main objective of this study. To this end, we used two strategies for analysis of this context: Map of Youth Leisure and Map Sports Places. The first attempt at understanding the behavior of youth and pleasure second, how the spaces are linked with this reality. The degradation of existence conditions has shown a direct relation with the decrease in identity projects to be experienced by young people. The impossibility of access to leisure services offered by the State may reinforce vulnerability experienced by people living in the outskirts of the city.

KEYWORDS: Adolescent Vinlence Leisure Activities 


\section{Introdução}

Quando pensamos juventude, há uma pressão por conta do senso comum de identificarmos sua existência a partir de uma narrativa unificada, abstrata e universal. Não há como sintetizar a alteridade marcante nessa fase da vida numa representação auto-explicativa ou autodeclaratória: "ser jovem é”. Isso significa que a experimentação desse projeto (a juventude) é alcançada a partir de uma multiplicidade ou complexidade de elementos que são formadores de identidade (HALL, 1999). Talvez fosse importante pensarmos na direção daquilo que é proposto por Carrano (2000): as juventudes são múltiplas.

O grande problema reside em como se referir à juventude sem excluir ou homogeneizar projetos tão distintos, apesar de algumas regularidades. Já não bastasse essa dificuldade (quanto ao que se quer dizer efetivamente quando pretendemos discutir sobre a juventude), a incorporação do predicado violência faz transbordar outros problemas para nossa análise.

A literatura analisada apresenta uma discussão sobre a violência em duas perspectivas. Uma, mais restritiva, associa violência com a questão dos crimes de homicídios. Num outro sentido, encontramos autores que fazem uma análise da violência a partir dos mecanismos sociais (material e simbólico) de sua produção. Para efeito deste trabalho, utilizaremos a expressão "crimes de homicídios" para tratar da análise mais restritiva do tema da violência. No sentido mais alargado, estão em pauta os processos sociais que produzem a violência como resultado do abandono dos direitos humanos (como o direito à cidadania) como princípio regulador de nossa civilidade.

Apesar da liberdade da agência, há um peso importante do contexto histórico e social que costura certas regularidades em nível de comportamento. No que concerne aos crimes de homicídios, um dos temas em pauta, Peres, Cárdia e Santos 
(2006) apontam que 87,6\% das vítimas de crime de homicídios são sujeitos entre 15 e 19 anos. Uma outra característica desses levantamentos é que o jovem negro se tornou um alvo prioritário desses crimes. Conforme Santa'Ana, Aerts e Lopes (2005), o assassinato de jovens negros é maior do que sua representação demográfica na cidade de Porto Alegre. Nesse caso, uma das formas de experimentar a identidade juvenil do jovem negro passa por esse impacto emocional: ser vítima privilegiada.

A pergunta que podemos fazer é: se eles (os jovens) são as principais vítimas, qual o objetivo de operar essa inversão e constituir um manual de periculosidade que os vitimiza prioritariamente? Uma hipótese que podemos colocar em suspensão diz respeito à incapacidade de incluir (para utilizarmos uma fala politicamente correta) alguns jovens no pleno gozo de seus direitos sociais, apontandose a exclusão propriamente dita (eliminação dos excedentes) ${ }^{1}$ como o destino inevitável dos indesejáveis.

Nesse sentido, a constituição de um discurso associando juventude e violência tem servido para deslocar o problema. A produção da juventude e da violência está diretamente associada ao modelo de sociedade que estamos construindo. Na centralidade do debate, está o desrespeito aos direitos humanos como mola propulsora da violência urbana, e não a existência de uma característica ontológica do sujeito jovem.

Em se tratando de juventude, não há como pensar esse desrespeito sem observarmos o que acontece no âmbito do lazer. Diferentes estudos apontam que o lazer é uma das principais atividades que permitem experimentar identidades. A falta de espaços e de serviços qualificados tem ampliado o volume de carências vividas por

1 Oliveira (1997). 
aqueles jovens moradores das regiões mais vulneráveis. Portanto, são limitadores que restringem a experimentação de projetos identitários lançados a partir do lazer.

Este trabalho tem por objetivo fazer uma análise do lazer de jovens do bairro Mário Quintana - periferia de Porto Alegre/RS, a partir de dois instrumentos de pesquisa: Mapa do Lazer Juvenil e Mapa dos Espaços de Lazer do Bairro Mário Quintana. Para pontuar com maior precisão o primeiro elemento da análise, torna-se importante constituir a base empírica deste nosso discurso. Isso não significa eliminar a possibilidade de a alteridade fazer parte deste trabalho e construir cenários que irão escapar ao escopo deste debate. Felizmente, não temos a preocupação de fundar uma narrativa única e universal sobre os eixos aqui propostos.

\section{Segregação, estigmatização e vulnerabilidade juvenil}

No contexto deste trabalho, a juventude possui um marcador de identidade fixo: morador do bairro Mário Quintana. Chegamos nela a partir de um estudo organizado para apoiar a Rede de Proteção da Criança e Adolescente da Região Nordeste na estruturação de estratégias para pensar o lazer de crianças e jovens do bairro. O Mapa do Lazer Juvenil do Bairro Mário Quintana teve como objetivo principal analisar o comportamento no âmbito do lazer dos jovens durante o final de semana.

A juventude que fez parte deste trabalho foi composta através de uma amostra de estudantes de escolas públicas da região. Participaram estudantes da sexta a oitava séries do ensino fundamental de cinco escolas, perfazendo um total de 279 sujeitos $^{2}$. Do sexo masculino, participaram 140 estudante (50,2\%); do sexo feminino, 139 estudantes (49,8\%). Desses, $45,3 \%$ se autodeclararam como sendo brancos, e

\footnotetext{
${ }^{2}$ Como não há escolas públicas de segundo grau dentro do bairro, os alunos de maior idade não puderam compor esta amostra. Cada escola houve um sorteio de três turmas para comporem a amostra.
} 
$54,7 \%$ foram classificados como negros ${ }^{3}$. De início, acreditamos que esses marcadores são suficientes para introduzirmos o debate. Ao longo do texto, apresentaremos outras informações que darão maior nitidez a esse cenário.

Para que a discussão possa trazer informações mais produtivas, vamos evitar fazer a leitura a partir do protagonismo juvenil na produção de crimes de homicídios. Casos emblemáticos, como o do jovem Champinha ${ }^{4}$, servem muito bem para ilustrar essa narrativa e constituir um cenário que tem pressionado o debate sobre a diminuição da maioridade penal. Dois equívocos impõem-se diante dessa realidade. O primeiro nega qualquer possibilidade de trazer para a superfície as reais possibilidades que o modelo disciplinar de nossa civilização possui para frear os impulsos primitivos. Nesse caso, a abordagem freudiana de Koltai (1999) parece ser bastante sugestiva. Para o autor, a agressividade compõe o universo do desejo e é instrumento e causa de gozo. O segundo desconsidera o papel da sociedade na produção da violência sobre os jovens, principalmente aqueles moradores de nossas periferias e ruas.

Muitas vezes, esse jovem é portador de uma série de vulnerabilidades (uma delas é não poder ser o sujeito de sua representação), o que acaba servindo de justificativa para estigmatizá-lo e justificar atos de violação dos direitos humanos. Esses jovens são vítimas de uma sociedade que lhes nega o direito de serem portadores de direitos (Adorno, Bordini e Lima, 1999). A privação dos direitos é uma marca dessa juventude.

A análise desse último equívoco permite explorar um determinado regime de verdade (estamos utilizando essa expressão nos termos apresentados pelo pensamento foucaultiano) que vitimiza aqueles que já foram alvos de violência da

\footnotetext{
${ }^{3}$ Eles se declararam como sendo possuidores das cores preta e parda.

${ }^{4}$ Jovem de 16 anos que planejou e executou a morte de dois outros jovens em São Paulo em 2003; a brutalidade do crime chocou o país.
} 
própria sociedade. Essa vitimização, que fragiliza e vulnerabiliza os jovens de periferia, é produzida por diferentes práticas discursivas. Uma análise nessa direção nos permitirá conhecer os diferentes projetos de juventude que são produzidos para e por eles.

Há uma pedagogia traçada no seio da sociedade que, antes mesmo que a agência possa se sentir livre para não aceitar as regras civilizatórias e fazer de seus instintos primitivos objeto de gozo, o violenta ao não garantir as bases fundamentais para o exercício de sua cidadania. A revisão da idade penal desloca o debate e imprime uma força discursiva que tem como objetivo a eliminação do convívio social de todos aqueles que foram produzidos como excluídos socialmente. Essa exclusão possui uma moldura incriminatória: jovem, do sexo masculino, morador da periferia e, preferencialmente, negro. O que escapa pode ser interpretado como uma imperfeição do sistema (estamos nos referindo aqui ao simbólico).

Para produzir ações que possam restabelecer uma normalidade civilizatórias, com a garantia dos direitos humanos de crianças e jovens, preceitos âncoras do Estatuto da Criança e do Adolescente (ECA), é preciso que a sociedade possa criar um outro cenário menos dramático para a experimentação da juventude. Um conjunto de direitos tem sido subtraído de alguns jovens. Dentre eles, podemos destacar: o direito a um local de moradia que lhe garanta experimentar uma melhor qualidade de vida, o direito à educação de qualidade, ao trabalho, ao lazer e à auto-representação.

As regiões mais vulneráveis a esse contexto são apresentadas como sendo espaços pouco confiáveis de nossa sociedade. Como sabemos, a principal finalidade da produção desse cenário é constituir uma distribuição mais homogênea dos extratos econômicos. Para dar legitimidade a essa prática social (o ato de segregar), a sociedade opera a partir dos marcos estabelecidos na legislação urbanística, a fim de garantir o 
distanciamento das classes indesejáveis e obter ganhos materiais e simbólicos com essa demarcação. Para os indesejáveis, restam apenas as áreas que são portadoras de um conjunto de vulnerabilidades. Conforme Rolnicki (1999, p.105), “[...] em um contexto de alta pressão demográfica e competição pelo solo urbano, o planejamento foi largamente utilizado como um instrumento para assegurar segregação e demarcação de segmentos de mercado".

A segregação apresenta uma faceta material: a localização no espaço geográfico da cidade. Outros marcadores são possíveis de serem apresentados: falta de saneamento básico, áreas de risco ou de proteção ambiental e com menor infra-estrutura de lazer. A sua outra faceta, a simbólica, busca estabelecer um regime de verdade que transforma a região e seus moradores em um conjunto de indesejáveis.

O Bairro Mário Quintana é produto desse modelo de urbanização. Reconhecido socialmente como uma região segregada, apresenta uma diversidade socioeconômica que é apagada no momento de sua representação. Preteceille (2004) aponta que há uma diversidade na formação do bairro popular, e isso dificulta a criação de indicadores capazes de dar precisão ao que se procura designar na ponta da representação, uma identidade única. Os problemas causados pela dificuldade de definição das unidades espaciais são equacionados através das definições políticoadministrativas das cidades. Nesse sentido, o Bairro Mário Quintana é mais uma demarcação político-administrativa do que portadora de uma identidade social prescritiva. Aliás, imputar uma identidade prescritiva faz parte da produção do estigma.

O bairro é composto por 26 setores censitários, que produzem uma complexa arquitetura. Os diferentes indicadores que utilizamos para criar um discurso com base empírica sólida (educação, densidade demográfica, renda e acesso à infra- 
estrutura) não nos permitem pensar numa homogeneidade das condições socioespaciais. Há determinadas regiões que, por acumularem um número maior de carências, acabam por criar determinadas regularidades, só percebidas no espaço micro do intra-bairro. Em outras, há uma diversidade que é permanentemente apagada.

Diversos autores apontam que a segregação espacial possui um peso importante na configuração de quadros que potencializam violências ${ }^{5}$. A segregação é um fenômeno urbano que força determinados grupos a se concentrarem em áreas precárias (TORRES, 2004; RODRIGUES e ARRIAGADA, 2004). Geralmente, são áreas desvalorizadas, em conseqüência de sua baixa infra-estrutura urbanística, que exigiriam muitos investimentos do mercado para agregarem valor - e são os únicos locais possíveis para o abrigo de famílias pobres. No entendimento de Wacquant (2001), por conta das múltiplas fragilidades, as regiões segregadas produzem um risco considerável à integridade física. É nessas regiões onde se dão as maiores incidências da pobreza, desemprego e violência (HUGHES, 2004). É nessas regiões que o acesso aos serviços públicos está fragilizado.

A segregação espacial é fruto da desigualdade social (CALDEIRA, 1997; RODRIGUES, 2004). Essa desigualdade não pode ser interpretada como capaz de apontar marcadores únicos e universais. Para Dubet (2001), na sociedade moderna, algumas desigualdades diminuíram e outras aumentaram. Elas são múltiplas e inesgotáveis. O Bairro Mário Quintana também é portador dessa dinâmica.

A universalização do acesso ao ensino básico, desigualdade que diminuiu em Porto Alegre, não significou um acesso de igual proporção ao conhecimento. $\mathrm{O}$ Mapa do Lazer Juvenil apontou que $61,7 \%$ da amostra possuem algum atraso escolar.

\footnotetext{
5 Rolnik (1999); Akerman e Bousquat (1999); Davis (2006); Freire (2005); Hughes (2004); Klisksberg (2002); Maricato (2000); Torres, Marques, Ferreira e Bitar (2003); Rodrigues e Arriagada (2004); Torres (2004); Ribeiro e Santos (2003); Wacquant (2001); Preteceille (1994, 1999, 2004); Caldeira (1997).
} 
Esse atraso, que aos 12 anos é nulo $(\mathrm{n}=37)$, aos 13 anos passa para $32 \%$ da amostra $(\mathrm{n}$ $=68)$; aos 14, esse valor salta para 62\% $(\mathrm{n}=67)$. Se computarmos que 107 estudantes que participaram do estudo já estão fora da idade referência para o ensino fundamental (idade superior a 15 anos), veremos que o acesso universalizado abriu espaço para produção de novas desigualdades. Quando o sucesso escolar (idade/ano e ciclo adequados) produz um cenário como o descrito a seguir, essa realidade torna-se ainda mais dramática: "Xico Mendes"6; "legar"; "fiquei caminhado" (fragmentos extraídos do questionário respondido pelos estudantes).

Diferentemente do que se poderia imaginar e do que é professado pelos arautos da globalização, o crescimento econômico tem amplificado ainda mais as desigualdades sociais (OLIVEIRA, 1997; BARCELOS, MAMMARELLA, 2001; DAVIS, 2006). No limite inferior dessa complexa arquitetura, estão os excluídos do sistema econômico, aqueles que estão fora do abrigo da economia internacional contemporânea (DAVIS, 2006). Não só bairros foram esquecidos por conta desse processo - no interior dessas comunidades, há regiões que foram completamente abandonadas, onde o Estado não tem nenhuma interferência na dinâmica social estabelecida (principalmente pelo crime organizado). Ter o jovem como vítima prioritária dessa exclusão social é o dado mais nítido daquilo que Maricato (2000) denominou de "tragédia urbana". A ordem econômica mundial está promovendo a super-urbanização, não pelo acesso ao emprego, mas sim pela reprodução violenta das condições degradantes de existência a que são submetidos contingentes cada vez mais crescentes da população mundial (DAVIS, 2006).

\footnotetext{
${ }^{6} \mathrm{O}$ nome do parque do bairro e de uma escola municipal é Chico Mendes.
} 
Não só as periferias são diferentes, como sinalizam Torres, Marques, Ferreira e Bitar (2003), como também as diferenças intra-bairro são importantes e reveladoras do papel do estigma na representação dessas localidades. É muito comum, nos bairros segregados, os moradores mais vulneráveis serem expostos a uma dupla estigmatização que compromete a coesão social. São moradores de bairros pobres e residem em regiões de completo abandono.

A estigmatização dos territórios que concentram a pobreza produz a cultura do medo e imprime um círculo vicioso que reforça as formas criminosas e perversas de solidariedade (RIBEIRO e SANTOS Jr, 2003). O estigma é uma forma perversa de constituir a imagem de quem deve ser objetivado. Ele não representa algo, e sim é a própria representação. Os elementos (ou figuras) que são pinçados da realidade para sua representação são escolhidos para garantir aderência direta e imediata ao que se procura objetivar e esconder, aquilo que representa uma contradição com o que se procura designar: a humanidade desses sujeitos. A partir dessa estratégia, os setores mais conservadores de nossa sociedade constroem o diagnóstico da periculosidade: jovens, do sexo masculino, oriundos de família de baixa renda, com baixa qualificação profissional, sem perspectiva de ingresso no mercado de trabalho formal e, na maioria, negros (MINAYO, 1994).

Ser um jovem morador do Bairro Mário Quintana não imputa, como já dissemos, uma identidade espacial única. Os loteamentos populares, as pequenas favelas e as invasões são substratos diferentes na configuração da identidade juvenil, que acaba incorporando toda sorte de preconceitos produzidos pela sociedade e reproduzidos pelos jovens como forma de estabelecer distinções intra-bairro. Um jovem morador de uma área de invasão é diferente daquele que reside em um loteamento popular. Porém, os 
dois são alvos da identidade produzida pelo estigma de ser morador do Bairro Mário Quintana.

Apartados do convívio com a cidade e com os outros, função ideológica importante da segregação socioespacial (RODRIGUES, 2004), cabe aos jovens indesejáveis a sentença final: o extermínio. "Da mesma forma que os exterminadores se constituem em grupo, as vítimas preferenciais do extermínio se expressam em segmentos e camadas identificados por possuírem atributos que importunam e se tornam insuportáveis a seus potenciais aniquiladores" (CRUZ-NETO e MINAYO, 1994, p. 203).

O estigma busca estabelecer um distanciamento espacial e emocional de pessoas e lugares. O estigma territorial “[...] serve para estimular práticas de diferenciação e distanciamento social interno que acabam diminuindo a confiança entre as pessoas, minando a solidariedade social em nível local" (WACQUANT, 2001, p. 163). A segregação socioespacial tem efeito negativo sobre o capital humano, pois acaba amplificando as vulnerabilidades já existentes (RODRIGUES e ARRIAGADA, 2004). É muito comum nos bairros periféricos que os espaços sejam loteados por gangues (identidades particulares). Essa demarcação restringe a mobilidade de todos.

Já não bastasse o acúmulo de carências, em decorrência da precária presença do Estado, o estigma imputa aos moradores das periferias um ônus ainda maior à sua existência - um ônus que é simbólico e que repercute na esfera material. Essa modalidade de violência (psíquica) produz desconfiança e serve como argumento justificativo à negação do outro como sujeito. Portanto, experimentar a juventude envolve múltiplas formas de negação. Como morador de uma determinada região, lhe é 
negado o direito de transitar em outra. Como morador de um bairro segregado, lhe é negado o direito de transitar pela cidade.

O motor principal para estabelecer estratégias de distanciamento social (negação) está alicerçado na imagem da violência (estigma) e nas taxas elevadas de homicídios, principalmente da população jovem. O Mapa do Lazer Juvenil não teve como objetivo principal discutir o tema da violência. Esse tema aparece de forma periférica no estudo, a fim de compreender como essa variável estabelece distinções na ocupação do lazer durante o final de semana. Quando perguntados sobre crimes de homicídios, 42,3\% da amostra disseram que conhecem alguém próximo que morreu de forma violenta. Em 78,4\% dos casos, as vítimas integravam o mesmo grupo etário em estudo (amigos, primos, irmãos e namorados). Esse resultado aponta que a morte por crime de homicídio está muito próxima dos jovens daquela comunidade. Portanto, evitar esse destino envolve algum tipo de negação da experimentação da juventude, por exemplo, diminuindo sua exposição pública. Como pode ser observado na Tabela 1 , na média, os turnos diurnos [sábado à tarde (ST), domingo pela manhã (DM) e domingo à tarde (DT)] garantem uma presença em casa de 51,5\% (ficar em casa e ter obrigações com o trabalho doméstico familiar (OTDF)). Assim, esses jovens experimentam a juventude como exílio.

A pobreza não leva, numa relação causal, à violência. O acúmulo de carências e/ou desvantagens, associado ao consumo de droga (lícitas ou ilícitas), é que produz um cenário explosivo. Não podemos deixar de destacar o papel desempenhado pelo tráfico de drogas no aprofundamento do quadro de violência nas regiões segregadas. No que se refere a essa realidade, o estudo apontou que $74,6 \%$ dos jovens possuem algum tipo de relação/contato com a maconha (considerando um missing de 
26,4\%): $13,9 \%$ dos que responderam a questão $(n=29)$ disseram que conhecem quem usa; $52,9 \%(n=110)$ já viram alguém fumando; para 13\% $(\mathrm{n}=27)$ alguém já ofereceu; 11,5\% $(\mathrm{n}=24)$ dos estudantes já seguraram na mão; $8,7 \%(\mathrm{n}=18)$ já experimentaram. No caso da cocaína/crack $55,2 \%$ dos estudantes $(n=154)$ se pronunciaram. Destes, $32,5 \%$ dos que responderam a questão $(n=50)$ disseram que conhecem quem usa; 44,2\% ( $\mathrm{n}=68)$ já viram alguém usando; para 14,3\% (n=22) alguém já ofereceu; 6,5\% $(n=10)$ dos estudantes já seguraram na mão; 2,6\% $(n=4)$ já experimentaram. Considerando que esses estudantes ainda estão ao alcance das agências sociabilizadoras (escolas, principalmente) e que sua permanência nelas diminui o risco de delinqüência, os que estão fora do sistema e perambulam pelas ruas da comunidade parecem ter um contato ainda mais próximo com este cenário explosivo.

Durante o ano de 2007, a disputa pelo controle do tráfico de drogas trouxe uma grande instabilidade à região. Toque de recolher, assassinato em plena luz do dia e confronto com a polícia marcaram o cotidiano do bairro. Não há como pensar a experiência da juventude a partir de uma assepsia que desconsidera o peso dessa realidade na construção dos sujeitos e dos tempos e espaços para produção do lazer.

Pensar essa problemática a partir do Rio Grande do Sul, estado com o terceiro melhor índice de desenvolvimento juvenil ${ }^{7}$, e de Porto Alegre, cidade reconhecida por possuir uma longa trajetória de investimento nos setores mais carentes, através do Orçamento Participativo (OP), serve para desfazer certos equívocos. É consenso na literatura acadêmica que os jovens são vítimas privilegiadas do crime por homicídio no Brasil. Porém, esse evento não tem impacto igual sobre todos os jovens. Análise de Sant'Ana, Aerts e Lopes (2005) sobre a criminalidade em Porto Alegre

\footnotetext{
7 Índice de Desenvolvimento Juvenil dos Estados Brasileiros (Fonte: UNESCO: Relatório de Desenvolvimento Juvenil, 2003).
} 
aponta que os jovens negros são vítimas privilegiadas. Neste caso, a exposição pública transforma a cor de suas peles em elemento distintivo na experimentação da juventude. Cabe aqui ressaltar que, nos territórios segregados, há uma presença maior de jovens negros do que a média na cidade. Enquanto que, para a cidade, os jovens negros representam 11\% da população, no bairro Mário Quintana, eles perfazem 45,3\%.

[...] embora sob o ponto de vista legal não haja discriminação, do ponto de vista das práticas sociais a cor ou a etnia funcionam como elementos que dificultam o acesso a bens e serviços oferecidos socialmente, uma vez que foi nas áreas do tipo inferior, na hierarquia sócio-espacial, que observamos os menores rendimentos, os mais baixos índices de instrução e os piores de saneamento básico (BARCELLOS, MAMMARELA e KOCH, 2002, p. 337).

Estudos a partir do Mapa do Lazer Juvenil do Bairro Guajuviras, localizado no município de Canoas (Região Metropolitana de Porto Alegre), que possui similitude na distribuição racial com o Bairro Mário Quintana em Porto Alegre, não apresentou diferenças estatísticas entre as opções de lazer de jovens negros e brancos (SANTOS, DAMICO e FREITAS, 2006). Um dos motivos para esse resultado está associado à baixa mobilidade urbana e a pouca oferta de opções de lazer no espaço intra-bairro. $\mathrm{O}$ lazer dos jovens pobres está circunscrito, prioritariamente, aos limites do local de moradia.

Uma das atividades importantes realizadas pelos jovens que aparece em diferentes levantamentos é a prática do esporte. Como bem retratam Brenner, Dayrell e Carrano (2005), o lazer juvenil é uma experiência cultural coletiva, e os esportes são espaços privilegiados para sua execução. Mas é nos bairros segregados que encontramos as piores condições para experimentação de atividades de cultura e lazer, dentre elas, as esportivas. 
A falta de acesso a espaços de lazer qualificados tem sido apontada como um dos fatores que atuam na fragilização de comunidades segregadas. No que tange aos espaços esportivos, esse problema está longe do alcance dos urbanistas $^{8}$. Primeiro, porque faltam indicadores que possam avaliar o grau de acesso a espaços esportivos. A estética ambiental tornou-se um regime de verdade que nega ao sujeito o direito de experimentar sua humanidade. O número absoluto de espaços (número de praças) não constitui uma boa alternativa. Segundo, porque a própria forma de expansão territorial, geralmente em direção às regiões mais vulneráveis, transforma vazios urbanos em locais de moradia. Nessas regiões, os espaços vazios rapidamente são congestionados.

O Bairro Mário Quintana abriga um dos principais parques de Porto Alegre, o Parque Chico Mendes. A primeira observação a ser pontuada é que a extensão territorial do bairro não permite o livre acesso de todos os seus moradores ao parque. Outra é que uma parte importante da área verde do parque foi invadida, produzindo uma sensação de insegurança. Essa sensação pressionou seu abandono, gerando um espaço privilegiado para desova de produtos roubados, principalmente carros, e corpos.

Santos (2006a), ao comparar a qualidade dos espaços de cinco parques da cidade de Porto Alegre através de indicadores criados para essa finalidade, como área esportiva $^{9}$, por exemplo, verificou que o Parque Chico Mendes possui a menor quantidade $\left(\mathrm{em} \mathrm{m}^{2}\right)$ e qualidade de espaços esportivos, comparativamente. $\mathrm{Na}$ contramão dessa realidade, a comunidade que possuí o parque com maior área esportiva e melhor qualidade em seus equipamentos localiza-se num dos bairros com maior renda per capita da cidade.

\footnotetext{
${ }^{8}$ Para análise crítica dessa realidade, ver Santos (2006a).

${ }^{9}$ A área esportiva (AE) é composta por dois outros indicadores: área esportiva construída (AEC) e área esportiva útil (AEU). A AEC é o somatório dos espaços construídos para a prática esportiva; a AEU é um percentual da área que, apesar de não possuir equipamento esportivo, permite sua apropriação para a prática esportiva.
} 
Nesse sentido, apesar de ter um parque dentro de seus limites geográficos, essa comunidade não possui uma área qualificada para a prática esportiva. Já as praças, que somam um total de oito, amplificam essa fragilidade. O Mapa dos Espaços Esportivo do bairro apontou importantes características das praças: desequilíbrio na distribuição dos equipamentos esportivos no espaço intra-bairro; praças construídas em ambientes cortados por valas; praças construídas em sobras de terreno cuja topografia em declive diminui a possibilidade de incorporar um maior volume de espaços para fins esportivos; é o único bairro da cidade onde todas as quadras são de chão batido; a única prática esportiva a ser experimentada é o futebol; há um número reduzido de equipamentos esportivos construídos (na média, um para cada espaço); inexistem áreas capazes de garantir atividades esportivas em condições climáticas restritivas ou impeditivas; inexistem serviços públicos de formação esportiva.

A má distribuição na malha urbana impede o acesso mais próximo de setores importantes do bairro, problema recorrente do planejamento urbano das cidades brasileiras. O espaço para a construção das praças é aquele que sobra após a implementação das áreas residenciais. Nas áreas de invasão, eles só são respeitados e garantidos quando são anteriores ao processo de expansão demográfica. Também não há projetos de reassentamento de famílias em áreas congestionadas, para qualificar espaços de convivência com a construção de equipamentos esportivos. Castro, Abramovay, Ruas e Andrade (2001) são enfáticos ao afirmarem que a ausência de equipamentos e atividades de lazer para a ocupação do tempo livre, principalmente em regiões carentes, abre uma porta a ser explorada pelo tráfico de drogas.

No que diz respeito à infra-estrutura esportiva, reforça-se aquela máxima: aos moradores da periferia, equipamentos públicos de baixo custo. Sem garantir uma 
multiplicidade de interesses esportivos e sem espaços qualificados, não há como fazer das praças uma âncora para uma política pública de esporte e lazer para a juventude. Essa realidade acaba por enfraquecer ainda mais os laços sociais da comunidade.

Ao visitarmos quatro das praças do Bairro Mário Quintana numa tarde ensolarada das férias de fevereiro de 2006, verificamos seu completo abandono. Intuímos que a principal motivação para essa realidade está associada ao desconforto térmico. Espaços distantes das residências, com pouca arborização e sem acesso a água compõem uma conjunção de fatores ideais para o distanciamento de seus potenciais usuários. Como garantir a dádiva da vida de Jacobs (2001) se os espaços são tão desqualificados?

Uma das canchas de bocha do Parque Chico Mendes, área reservada para a prática de um esporte de grande valor regional que exige dimensões reduzidas quando comparado com uma quadra de futebol, foi o único espaço onde encontramos duas equipes, com pequeno número de praticantes jogando. O detalhe que vem a corroborar para o argumento utilizado no parágrafo anterior é que, ao lado dessa quadra, havia um bebedouro, e a quadra possuía uma cobertura que não permite a incidência direta dos raios solares. Portanto, pensar numa política pública que promova o lazer em comunidades que acumulam carências não pode se descuidar desses aspectos. $\mathrm{Na}$ realidade, os investimentos nessa área não estão tendo o impacto necessário para a construção de uma rede de solidariedade voltada para uma manifestação cultural e esportiva, de tamanha importância na formação de crianças e jovens e que permitiriam a produção de múltiplos projetos de identidades.

Por outro lado, é preciso destacar também que o acesso à aprendizagem esportiva em espaços públicos está restrito ao que é ofertado pelas aulas de educação 
física. Há apenas um espaço coberto para a prática esportiva, localizado no interior de uma das escolas. Cabe perguntar aos gestores públicos: como garantir aderência a programas esportivos se a continuidade de uma prática é comprometida através de eventos climáticos restritivos que impedem sua experimentação a céu aberto?

Apenas 7,89\% dos participantes do Mapa do Lazer Juvenil do bairro ( $\mathrm{n}=$ 18) desenvolvem atividades formadoras no âmbito esportivo. Destes, 14 com a prática do futebol, três com tênis de mesa (projeto desenvolvido por uma escola do bairro) e um com a capoeira. Essa realidade traduz com bastante nitidez como o Estado brasileiro atua na amplificação das carências para um público já fragilizado por um conjunto de desvantagens. Como refazer o circuito de reciprocidades positivas apontados por Zaluar (2002) se uma das principais portas de acesso às crianças e jovens das periferias a um espaço formador está interditada? Nesse sentido, concordamos com Zaluar, Noronha e Albuquerque (1994) quando dizem que não é a pobreza a causa da violência nas periferias das cidades, mas sim a fraqueza institucional do Estado brasileiro em garantir direitos previstos em nossa constituição.

Durante os cinco turnos investigados pelo Mapa do Lazer Juvenil - sábado à tarde $(\mathrm{ST})$, sábado à noite $(\mathrm{SN})$, domingo pela manhã $(\mathrm{DM})$, domingo à tarde (DT), domingo à noite $(\mathrm{DN})$-, identificamos que o esporte desempenha um papel importante no lazer dos jovens. Ele aparece sempre entre as cinco principais atividades apontadas pelos estudantes, conforme a TAB. 1, porém, muito abaixo de resultados alcançados por outros estudos dessa natureza.

Cabe destacar o peso do trabalho realizado no interior das residências. Exceto pelo ST, nos outros cenários, trata-se da principal atividade desenvolvida pelos estudantes. Para uma população que tem carência na oferta de espaços e atividades 
qualificados para o desenvolvimento do lazer, ocupar o tempo com Obrigações com o Trabalho Doméstico Familiar $\left(\mathrm{OTDF}^{10}\right)$ traduz a dificuldade de romper com um modelo de formação que vincula, principalmente as meninas, a atividades restritas ao espaço doméstico (BRENNER, DAYRELL e CARRANO, 2005). A atividade religiosa também aparece em todos os cenários entre as cinco principais atividades. Em outro trabalho, já identificamos o importante papel desempenhado pelas igrejas na dinamização de atividades de lazer voltadas aos jovens (SANTOS E MANDARINO, 2005).

TABELA 1

Principais atividades de lazer durante o final de semana dos estudantes.

\begin{tabular}{l|c|c|c|c|c|c|c|c|c|c}
\hline Atividades & ST & $\%$ & SN & $\%$ & DM & $\%$ & DT & $\%$ & DN & $\%$ \\
\hline Ficar em casa & 92 & 33 & 165 & 59,2 & 176 & 63,1 & 103 & 36,9 & 192 & 68,8 \\
Esporte & 94 & 33,7 & 14 & 5,0 & 24 & 8,6 & 75 & 26,9 & 09 & 3,2 \\
Ativ. religiosa & 14 & 5,0 & 18 & 6,5 & 08 & 2,9 & 15 & 5,4 & 13 & 4,7 \\
Ficar c/ amigos & 14 & 5,0 & 22 & 7,9 & - & - & 15 & 5,4 & 18 & 6,5 \\
OTDF & 16 & 5,7 & - & - & 30 & 10,8 & 14 & 5,0 & 09 & 3,2 \\
Ir a festas & - & - & 29 & 10,4 & - & - & - & - & - & - \\
Trabalho & - & - & - & - & 06 & 2,2 & - & - & - & - \\
Outros & 49 & 17,6 & 31 & 11 & 35 & 12,4 & 57 & 20,4 & 38 & 13,6 \\
Total & 279 & 100 & 279 & 100 & 279 & 100 & 279 & 100 & 279 & 100 \\
\hline
\end{tabular}

Já as atividades culturais, que também desempenham um papel importante na formação das crianças e jovens, são garantidas apenas pelo escasso número de vagas oferecidas pelas escolas públicas da região. A participação em grupos de dança $(n=31)$, teatro $(\mathrm{n}=5)$ e música $(\mathrm{n}=5)$ representa $14,7 \%$ da amostra. A baixa oferta de espaços/serviços culturais, quando associada à falta de recursos financeiros das famílias, produz um cenário desolador do ponto de vista da experimentação dessas atividades

\footnotetext{
${ }^{10}$ Essas atividades envolvem o cuidado com a casa (lavar, cozinhar, varrer e passar) e com os irmãos menores.
} 
durante o lazer de final de semana. Quando procuramos analisar o comportamento de lazer dos estudantes durante o final de semana, as atividades culturais acabaram por denunciar "O tamanho da tragédia" (Revista Aplauso, 2007). No levantamento elaborado pelo Ministério da Cultura/Ipea, a falta de acesso aos produtos culturais no país é resultado de múltiplos fatores. Dentre eles, podemos destacar: concentração das atividades culturais em áreas centrais, falta de recursos financeiros das famílias pobres e falta de formação para compreender o significado das diferentes artes.

As atividades culturais do Mapa do Lazer Juvenil que apareceram no estudo foram: cinema, leitura e visitação à Feira do Livro. Para efeitos desta análise, excluímos a ida a shows. No sábado à tarde, a participação dos jovens em atividades culturais foi de $1,1 \%(\mathrm{n}=3)$; no sábado à noite, $0,4 \%(\mathrm{n}=1)$; no domingo pela manhã, $0,4 \%$; no domingo à tarde, $0,7 \%(\mathrm{n}=2)$; no domingo à noite, $0,4 \%$. A negação desse universo da cultura impõe restrições na experimentação de identidades.

Um outro dado que traduz de forma bastante clara o grau de privações a que estão submetidos os estudantes do bairro diz respeito às possibilidades de circulação para aproveitarem as atividades de lazer que a cidade oferece. Em média (levando em consideração os cinco turnos investigados), somente $17 \%$ dos estudantes conseguem sair do bairro em algum turno. Condenados por não poder experimentar a cidade, esses jovens vivem em um bairro de exílio sem espaços qualificados para o lazer, o que desqualifica a vida de toda coletividade (WACQUANT, 2001; ABRAMOVAY e CASTRO, 2002). Infelizmente são os bairros segregados que apresentam uma menor qualidade dos espaços de lazer que poderia diminuir o impacto das múltiplas vulnerabilidades que estão submetidos (CESTARO, 2005). 
Mesmo no espaço intra-bairro, a circulação não é feita ao acaso, sem roteiro, pois a exclusão não torna as massas homogêneas (ZALUAR, 2000). As formas de ocupação do espaço constroem determinadas práticas sociais que regulam o livre trânsito de seus moradores no pedaço (MAGNANI, 1992). O bairro exilado pode apresentar, ainda, regiões segregadas por conta, por exemplo, de disputas do tráfico de drogas ou de gangues que controlam determinadas regiões. Consequentemente, “[...] pertencer ao pedaço significa também poder ser reconhecido em qualquer circunstância, o que implica o cumprimento de determinadas regras de lealdade que até mesmo os bandidos da vila, de alguma forma, aceitam" (MAGNANI, 1992, p. 193).

Apesar de todos os participantes do Mapa do Lazer Juvenil serem moradores de um bairro segregado, suas experiências são marcadas por elementos que produzem múltiplos cenários para viver a juventude. Esses jovens são alvos de um processo de vitimização e da supressão de direitos. O lazer, que poderia ser uma importante âncora na produção de uma multiplicidade de projetos identitários, acaba reforçando aquilo que se procura combater: a produção da vulnerabilidade juvenil.

\section{Conclusão}

Não há como pensarmos a segregação como destino necessário das populações pobres em direção à convivência com um contexto que desqualifica suas vidas. É a não-presença do Estado que tem contribuído sobremaneira para a degradação humana e ambiental dessas regiões. Esse é o pano de fundo em que os jovens do Bairro Mário Quintana vão experimentando seus projetos de identidades. As restrições, desvantagens ou carências a que estão submetidos pressionam setores importantes para a convivência cotidiana com uma expressão marcante da violência: os crimes de homicídios. 
Como pode ser observado no Mapa do Lazer Juvenil, a necessidade de distanciamento dessa realidade restringe a mobilidade ao espaço da residência. A realidade das praças funciona como uma engrenagem que força o abandono e produz um cenário inóspito que retroalimenta a violência. Essa experiência não é vivida por todos da mesma forma, porém, o estigma produzido pelos indicadores dos crimes de homicídios acaba unificando uma identidade que deprime ainda mais a comunidade. Para serem fortalecidas as diferentes identidades, é preciso que se garantam aos jovens uma melhor qualidade de vida, acesso aos direitos sociais básicos (dentre eles o lazer) e o direito à representação.

\section{REFERÊNCIAS}

ABRAMOVAY, Miriam; CASTRO, Mary Garcia. Jovens em situação de pobreza, vulnerabilidades sociais e violência. Cadernos de Pesquisa, São Paulo, n. 116, p.143176, jul. 2002.

ADORNO, Sérgio; BORDINI, Eliana; LIMA, Renato Sérgio de. O adolescente e as mudanças na criminalidade urbana. São Paulo em Perspectiva, São Paulo, v. 13, n. 4, p. 62-74, out./dez.1999.

AKERMAN, Marco; BOUSQUAT, Aylene. Mapas de risco de violência. São Paulo em Perspectiva, São Paulo, v. 13, n. 4, p. 112-120, out./dez. 1999.

BARCELLOS, Tanya M.; MAMMARELLA, Roseta. Questões teóricas e metodológicas na pesquisa recente sobre as grandes cidades: notas para reflexão. Ensaios FEE, Porto Alegre, FEE, v. 22, n. 2, p. 248-269. 2001.

BARCELlOS, Tanya; MAMMARELLA, Roseta; KOCH, Mirian Regina. Tipologia sócio-espacial 1980-91: diferença sócio-ocupacionais e desigualdades sociais entre os espaços da cidade. Indicadores Econômicos FEE, Porto Alegre, v. 29, n. 4, p. 307 $341,2002$.

BRENNER, Ana Karina; DAYRELL, Juarez; CARRANO, Paula. Cultura do lazer e do tempo livre dos jovens brasileiros. In: ABRAMO, Helena Wendel; BRANCO, Pedro Paulo (org.) Retrato da Juventude brasileira: análise de uma pesquisa nacional. São Paulo: Instituto Cidadania/Editora Fundação Perseu Abramo, 2005. p. 175-214.

CALDEIRA, Teresa. Enclaves fortificados: a nova segregação urbana. Novos Estudos CEBRAP, São Paulo, n. 47, p. 127-154, mar. 1997. 
CARRANO, Paula. Juventudes: as identidades são múltiplas. Revista Movimento, Faculdade de Educação da UFF, Rio de Janeiro, v. 2, n. 1, 2000, p. 11-27.

CASTRO, Mary Garcia.; ABRAMOVAY, Mirian.; RUAS, Maria das Graças.; ANDRADE, Eliane Ribeiro. Cultivando vida, desarmando violência: experiências em educação, cultura, lazer, esporte e cidadania com jovens em situação de pobreza. Brasília: UNESCO/Brasil Telecom, Fundação Kellogg, Banco Interamericano de Desenvolvimento, 2001.

CESTARO, Lucas. Lazer e segregação sócio-espacial: levantamento das áreas destinadas ao sistema de lazer do município de Piracicaba, Estudos Geográficos, Rio Claro, v. 3, n. 2, p. 54-65, dezembro. 2005.

CRUZ-NETO, Otavio.; MINAYO, Maria Cecília. Extermínio: violentação e banalização da vida. Caderno de Saúde Pública, Rio de Janeiro, 10 (Supl. 1), p. 199212, 1994.

DAVIS, Mike. Planeta Favela; Tradução de Beatriz Medina. São Paulo: Boitempo, 2006.

DUBET, François. As desigualdades multiplicadas. Revista Brasileira de Educação, Rio de Janeiro, n. 17. p. 5-19, mai./ago. 2001.

FREIRE, Helena Barone. Sistemas de lazer e violência urbana: estudo da relação no Município de Piracicaba - SP. 256 f. Dissertação (Mestrado) - Escola Superior de Agricultura Luiz de Queiroz, USP, Piracicaba, 2005.

HALL, Stuart. A identidade cultural na pós-modernidade. Tradução de Tomaz Tadeu da Silva, Guacira Lopes Louro. Rio de Janeiro: DP\&A, 1999.

HUGHES, Pedro Javier Aguerre. Segregação socioespacial e violência na cidade de São Paulo: referências para a formulação de políticas públicas, São Paulo em Perspectiva, São Paulo, v. 18, n. 4, p. 93-102, out./dez. 2004.

INSTITUTO BRASILEIRO DE GEOGRAFIA E ESTATÍSTICA - IBGE. Censo de 2000. Disponível em: <http: //www.ibge.gov.br>. Acesso em: 5 de nov. 2007.

JACOBS, Jane. Morte e vida de grandes cidades. São Paulo: Martins Fontes, 2001.

KLISKSBERG, Bernardo. América Latina: uma região de risco - pobreza, desigualdade e institucionalidade social. Tradução de Norma Guimarães. Brasília: UNESCO, 2002.

KOLTAI, Caterina. Violência e indiferença: duas formas de mal-estar na cultura. São Paulo em Perspectiva, São Paulo, v. 13, n. 3, p. 76-80, jul./set. 1999.

MAGNANI, José Guilherme Cantor. Da periferia ao centro: pedaços e trajetos. Revista de Antropologia, São Paulo, USP, v. 35, p. 191-203, 1992. 
MARICATO, Ermínia. Urbanismo na periferia do mundo globalizado: metrópoles brasileiras. São Paulo em Perspectiva, São Paulo, v. 14, n. 4, p.21-33, out./dez. 2000.

MINA YO, Maria Cecília. A violência sob a perspectiva da saúde pública. Cadernos de Saúde Pública, Rio de Janeiro, 10 (Supl. 1), p. 7-18, 1994.

OLIVEIRA, Luciano. Os excluídos "existem"? Notas sobre a elaboração de um Novo conceito. Revista Brasileira de Ciências Sociais, São Paulo, n. 3, v. 12, p. 49-61, fev. 1997.

PERES, Maria Fernanda Tourinho.; CARDIA, Nancy.; SANTOS, Patrícia Carla. Homicídio de crianças e jovens no Brasil: 1980-2002. Núcleo de Estudos da Violência, Universidade de São Paulo, SP: NEV/USP, 2006.

PRÉTECEILLE, Edmundo. Cidades Globais e segmentação social. In: RIBEIRO, L. C. Q.; SANTOS Jr., O. A. (Org.) Globalização: fragmentação e reforma urbana e o futuro das cidades brasileiras. Rio de Janeiro: Civilização Brasileira, 1994. p. 65-89.

PRÉTECEILLE, Edmundo. A construção social da segregação urbana: convergências e divergências. Tradução de Daniel Julien Van Wilderode. Espaço \& Debate, São Paulo, v. 24, n. 45, p. 11-23, 2004.

PRÉTECEILLE, Edmundo.; RIBEIRO, Luiz César de Queiroz. Tendências da segregação social em metrópoles globais e desiguais: Paris e Rio de Janeiro nos anos

80. Revista Brasileira de Ciências Sociais, São Paulo, v. 14, n. 40, p. 143-162, jun.1999.

REVISTA APLAUSO: cultura em revista. Porto Alegre: Grupo Amanhã, Edição 86, set, 2007.

RIBEIRO, Luiz César de Queiroz.; SANTOS Jr., Orlando Alves., O. A. Democracia e segregação urbana: reflexões sobre a relação entre a cidade e a cidadania na sociedade brasileira. Revista EURE, Santiago do Chile, v. XXIX, n. 88, p. 79-95, dic. 2003.

RODRIGUES, Ana Lúcia. A pobreza mora ao lado: segregação socioespacial na região metropolitana de Maringá. 258 f. Tese (Doutorado) - Doutorado em Ciências Sociais, PUC, São Paulo, 2004.

RODRIGUES, Jorge; ARRIGADA, Camilo. Segregación residencial em la ciudad latinoamericana. Revista EURE, Santiago do Chile, v. 15, n. 89, p. 5-24, dic. 2004.

ROLNIK, Raquel. Exclusão Territorial e violência. São Paulo em Perspectiva, São Paulo, v. 13, n. 4, p. 100-110. out./dez. 1999.

SANT’ANA, Ana.; AERTS, Denise.; LOPES, Maria Julia. Homicídios entre adolescentes no sul do Brasil: situação de vulnerabilidade segundo seus familiares. Caderno de Saúde Pública, Rio de Janeiro, v. 21, n. 1, p. 120-129, jan./fev. 2005. 
SANTOS, Edmilson Santos. Espaços esportivos de parques públicos da cidade de Porto Alegre: uma análise comparativa, Revista Digital, Buenos Aires, 2006a. Disponível em: <http://www.efdeportes.com/efd92/parques.htm> Acesso em: 3 março 2008.

SANTOS, Edmilson Santos.; DAMICO, José Geraldo; FREITAS, Luis Antônio Carvalho. Pensando o lazer a partir da perspectiva étnica. Revista Arquivos em Movimento, v. 2, n. 2, p. 36-54, jul./dez 2006.

SANTOS, Edmilson Santos.; MANDARINO, Claudio Marques. Juventude e religião: cenários no âmbito do lazer. Revista de Estudo da Religião, São Paulo, n. 3, p. 161$177,2005$.

TORRES, Haroldo da Gama. Segregação residencial e políticas públicas em São Paulo na década de 1990. Revista Brasileira de Ciências Sociais, São Paulo, v. 19, n. 54, p. 41-56, fev. 2004.

TORRES, Haroldo da Gama; MARQUES, Eduardo; FERREIRA, Maria Paula; BITAR, Sandra. Pobreza e espaço: padrões de segregação em São Paulo. Estudos Avançados, São Paulo, v. 17, n. 47, p. 97-128, 2003.

WACQUANT, Loic. Os condenados da cidade. RJ: Revan/Fase, 2001.

ZALUAR, A. A máquina e a revolta: as organizações populares e o significado da pobreza. 2ed., São Paulo: Brasiliense, 2000.

Oito temas para debate: violência e segurança pública. Sociologia Problemas e Práticas, Lisboa, v. 38, p. 19-24, mai. 2002.

; NORONHA, José C.; ALBUQUERQUE, Ceres. Violência: pobreza ou fraqueza institucional? Caderno de Saúde Pública, Rio de Janeiro, 10 (supl. 1), p. 213 217, 1994.

\section{Endereço do Autor:}

Edmilson Santos dos Santos

Av. Guilherme Schell 1250 casa 48

Bairro Rio Branco

Canoas - RS - 92200-630

Endereço Eletrônico: profedsantos@yahoo.com.br 